\title{
Waves of SARS-CoV-2 Infection and Blood Coagulation-A Link and Beyond
}

\author{
Job Harenberg ${ }^{1,2} \quad$ Francesco Violi ${ }^{2}$ \\ ${ }^{1}$ Medical Faculty Mannheim, Ruprecht-Karls-University, Heidelberg, \\ Germany \\ 2 DOASENSE GmbH, Heidelberg, Germany \\ ${ }^{3}$ Department of Internal Medicine, Anesthesiology and \\ Cardiovascular Sciences, Sapienza University of Rome, Rome, Italy \\ Thromb Haemost 2021;121:4-6.
}

In 2020, the coronavirus disease (COVID-19) pandemic caused by the severe acute respiratory syndrome coronavirus-2 (SARS-CoV-2) presented a major health problem, forcing people to work from home in an effort to contain the virus. The pandemic generated opportunities for research in many areas. In the first phase of the pandemic, a great number of scientific reports were published on SARS$\mathrm{CoV}-2$. These reports generated further scientific questions, which have become even more relevant now that we are experiencing a second wave of infections. Thromboembolic events contribute to up to $20 \%$ of COVID-19-related mortality, ${ }^{1}$ making this a highly important research topic.

\section{Pathophysiology}

COVID-19 is characterized not only by acute severe respiratory syndrome needing intensive care unit treatment but also by venous and arterial thrombosis, ${ }^{2}$ including prolonged prothrombin time, activated partial thromboplastin time, reduced platelet count, and elevated D-dimers. ${ }^{3}$

There is a growing body of evidence that the SARS-CoV-2 virus infects the body via interaction of its spike protein with angiotensin-converting enzyme 2 (ACE2), which is expressed in the lung, heart, vascular system, gastrointestinal tube, kidney, and other organs. ${ }^{4}$ The infection mechanism includes:

- Virus entry into cells upon spike protein cleavage by a serine protease transmembrane protease serine subtype 2 (TMPRSS2). $^{5}$

- Downregulation of surface ACE2 expression and upregulation of angiotensin II (Ang II) correlating with viral load. ${ }^{6}$

- Ang II-induced proinflammatory changes in the arterial endothelium, vascular infiltration of monocytes, and oxidative stress-mediated vascular dysfunction. ${ }^{7}$

received

November 16, 2020

accepted

November 17, 2020

Address for correspondence Job Harenberg, MD, DOASENSE GmbH, Waldhofer Strasse 102, D-69123 Heidelberg, Germany (e-mail: j.harenberg@doasense.de).

- Ang II interaction with type 1, 2, and 4 angiotensin receptors, causing leukocytes to adhere to endothelial cells, exerting a prothrombotic response and increasing fibrin and plasminogen activator inhibitor 1 production. ${ }^{8}$

- Activation of NADPH oxidase 2 (Nox2) by Ang II, increasing reactive oxidant species production associated with thrombotic events. ${ }^{9}$

- Nox2 activation promotes prothrombotic effects by biosynthesis of isoprostane and tissue factor, and inactivation of nitric oxide, a vasodilating and antiaggregating molecule. $^{10}$

- Toll-like receptor (TLR7) activates platelets, forming platelet-neutrophil aggregates and neutrophil extracellular $\operatorname{traps}^{11}$ (-Fig. 1).

- Elevated mannose-binding lectin initiates lectin-mediated complement activation correlating with D-dimer levels. $^{12}$

- Endotoxemia enhances lipopolysaccharides, activating platelets and blood clotting via TLR4 ${ }^{13}$ (-Fig. 1).

\section{Anticoagulant Treatment: Heparins}

Critically ill nonbleeding patients with disseminated intravascular coagulation and virus-induced sepsis are typically treated by therapeutic doses of unfractionated heparin or low molecular weight heparin (LMWH) according to guidelines of the International Society of Thrombosis and Haemostasis. However, there is no direct evidence that this treatment is beneficial $^{14}$ for COVID-19 patients. ${ }^{15}$

Guidelines issued by the American Society of Hematology, American Society of Cardiology, Spanish Society of Cardiology, World Health Organization, National Institutes of Health, ${ }^{16}$ Italian Society for Thrombosis and Haemostasis, ${ }^{17}$ and VASEuropean Independent Foundation in Angiology/Vascular Medicine $^{18}$ are based on retrospective studies only. Most guidelines agree that LMWH should be used at prophylactic

(c) 2021. Thieme. All rights reserved. Georg Thieme Verlag KG,

Rüdigerstraße 14,

70469 Stuttgart, Germany
DOI https://doi.org/ 10.1055/s-0040-1721778. ISSN 0340-6245. 


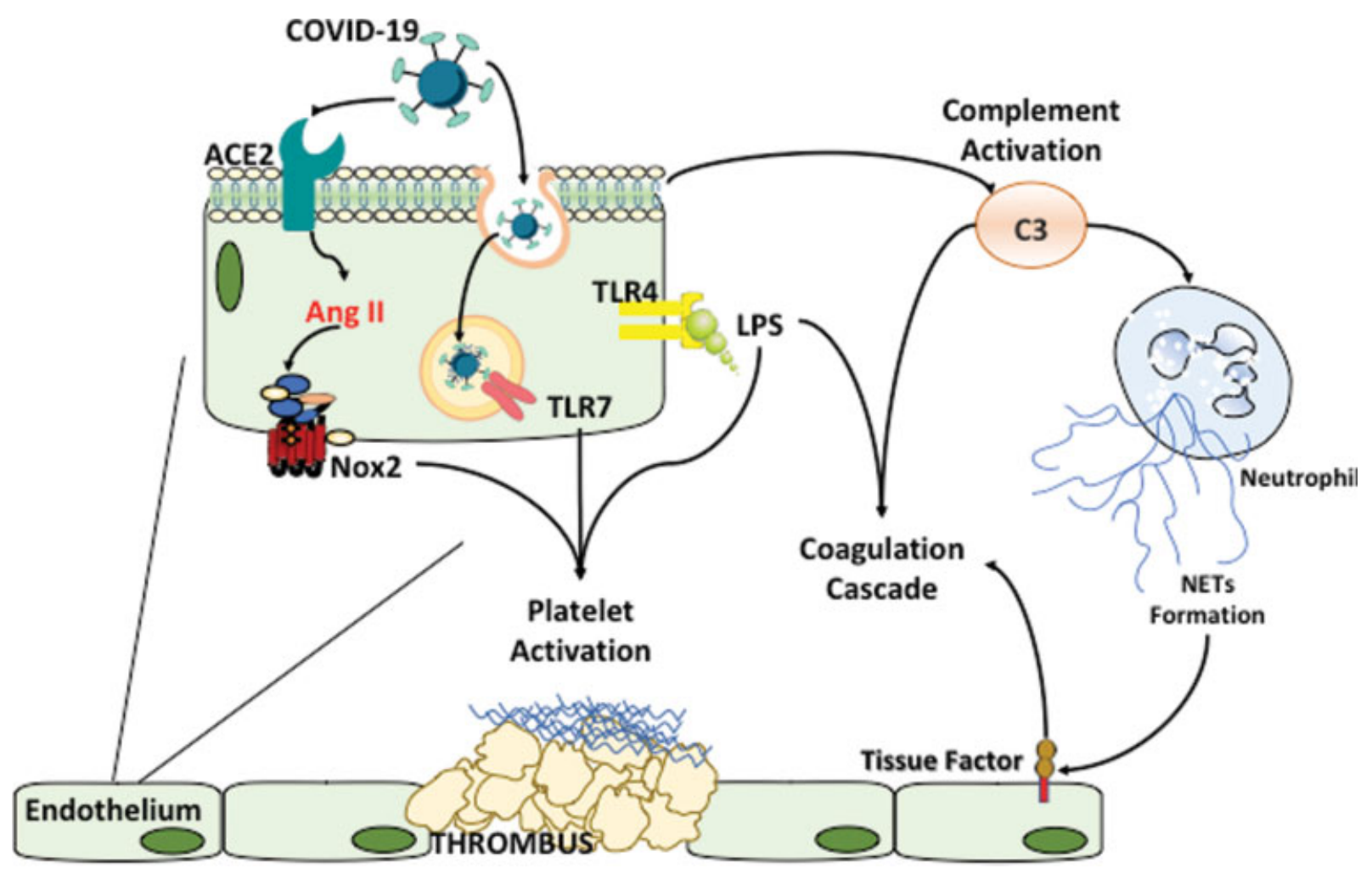

Fig. 1 COVID-19 and thrombosis: mechanisms of action. For explanation refer to Pathophysiology. COVID-19: Coronavirus disease 2019. ACE2, angiotensin-converting enzyme 2; Ang II, angiotensin II; TLR4, 7, Toll-like receptor 4 or 7; Nox2, NADPH oxidase 2; LPS, lipopolysaccharides; C3, complement 3; NETs, neutrophil extracellular traps.

doses. Many of them have suggested that LMWH should be used at intermediate or therapeutic doses in high-risk COVID19 patients. ${ }^{19,20}$

\section{Anticoagulant Treatment: Direct Oral Anticoagulants}

COVID-19 symptoms and thrombotic-inflammatory processes start days after initial infection with SARS-CoV-2, when patients are not hospitalized. ${ }^{21}$ Upon hospitalization, low dose apixaban (odds ratio [OR] $0.46, p=0.001$ ), therapeutic dose apixaban (OR $0.57, p=0.006$ ), and enoxaparin prophylaxis (OR 0.49, $p=0.001$ ) have all been associated with a significant decrease in mortality of hospitalized COVID-19 patients. Low and high doses of unfractionated heparin have shown no benefit. In addition, bleeding complications were not more frequent in patients receiving anticoagulant therapy compared with patients without anticoagulant therapy. ${ }^{22}$ Upon discharge from hospital risk of venous thromboembolism (VTE) still remains. The effects of treatment with the direct oral factor Xa inhibitors apixaban, edoxaban, and rivaroxaban have been investigated during in-hospital and posthospital care of COVID-19 patients. ${ }^{23}$ Switching from LMWH to dabigatran or edoxaban is investigated at creatinine clearances of $>30 \mathrm{~mL} / \mathrm{min}$ and 30 to $15 \mathrm{~mL} / \mathrm{min}$, respectively. ${ }^{24}$ The decision to switch from vitamin $\mathrm{K}$ antagonist to LMWH is determined by international normalized ratio and to direct oral anticoagulants by LMWH-independent rapid and accurate testing using patient urine samples. ${ }^{25}$
Currently, more than 10 studies are testing different anticoagulant regimes in thousands of hospitalized and discharged COVID-19 patients in an effort to prevent the combined outcomes of VTE and mortality. ${ }^{26}$

\section{Additional Anticoagulant Treatment Options}

Histones, neutrophil elastase, interleukin-8, and other toxic basic proteins are released into the pulmonary system in diseases such as asthma, cystic fibrosis, and acute respiratory distress syndrome. These and other basic proteins are toxic to the endothelium and are neutralized by the negatively charged intrapulmonary administered nebulized heparin ${ }^{27}$ (NCT04530578, NCT04466670). Designer heparin molecules that can better interact with heparan sulfate on the surface of the SARS-CoV-2 virus have been developed to improve COVID-19 therapy. ${ }^{28}$

Other treatment options include administration of intravenous immunoglobulin $G$, tissue plasminogen, activated protein $\mathrm{C}^{29}$ and thrombomodulin. ${ }^{30}$ One report has shown that administration of albumin reduces mortality in COVID19 patients. $^{31}$

\section{Future Perspectives}

Investigations into the pathophysiology and treatment of COVID-19 will continue into a next phase of the pandemic, when vaccination of the population will be introduced, 
targeting blood coagulation, the immune system, and the occurrence of thromboembolism.

Once the ongoing prospective randomized controlled trials and other and adequately powered studies on anticoagulation in COVID-19 patients are completed, meta-analyses and indirect treatment comparisons can be performed to analyse efficacy and safety of different treatments and identify optimal risk-based antithrombotic strategies for treating COVID-19 patients, both in hospital and following discharge.

\section{Conflict of Interest}

None declared.

\section{References}

1 Bikdeli B, Madhavan MV, Gupta A, et al;Global COVID-19 Thrombosis Collaborative Group. Pharmacological agents targeting thromboinflammation in COVID-19: review and implications for future research. Thromb Haemost 2020;120(07):1004-1024

2 Mackman N, Antoniak S, Wolberg AS, Kasthuri R, Key NS. Coagulation abnormalities and thrombosis in patients infected with SARS-CoV-2 and other pandemic viruses. Arterioscler Thromb Vasc Biol 2020;40(09):2033-2044

3 Violi F, Pastori D, Cangemi R, Pignatelli P, Loffredo L. Hypercoagulation and antithrombotic treatment in coronavirus 2019: a new challenge. Thromb Haemost 2020;120(06):949-956

4 Bilaloglu S, Aphinyanaphongs Y, Jones S, Iturrate E, Hochman J, Berger JS. Thrombosis in hospitalized patients with COVID-19 in a New York city health system. JAMA 2020;324(08):799-801

5 Zhang S, Liu Y, Wang X, et al. SARS-CoV-2 binds platelet ACE2 to enhance thrombosis in COVID-19. J Hematol Oncol 2020;13 (01):120

6 Liu Y, Yang Y, Zhang C, et al. Clinical and biochemical indexes from 2019-nCoV infected patients linked to viral loads and lung injury. Sci China Life Sci 2020;63(03):364-374

7 Molitor M, Rudi WS, Garlapati V, et al. Nox2+ Myeloid cells drive vascular inflammation and endothelial dysfunction in heart failure after myocardial infarction via angiotensin II receptor type 1. Cardiovasc Res 2020. Doi: 10.1093/cvr/cvaa042

8 Mogielnicki A, Chabielska E, Pawlak R, Szemraj J, Buczko W. Angiotensin II enhances thrombosis development in renovascular hypertensive rats. Thromb Haemost 2005;93(06):1069-1076

9 Violi F, Oliva A, Cangemi R, et al. Nox2 activation in Covid-19. Redox Biol 2020;36:101655

10 Violi F, Carnevale R, Loffredo L, Pignatelli P, Gallin JI. NADPH oxidase2 and atherothrombosis: insight from chronic granulomatous disease. Arterioscler Thromb Vasc Biol 2017;37(02):218-225

11 Le Joncour A, Biard L, Vautier M, et al. Neutrophil-platelet and monocyte-platelet aggregates in COVID-19 patients. Thromb Haemost 2020;120(12):1733-1735

12 Eriksson O, Hultström M, Persson B, et al. Mannose-binding lectin is associated with thrombosis and coagulopathy in critically Ill COVID-19 patients. Thromb Haemost 2020;120(12):1720-1724

13 Cangemi R, Pignatelli P, Carnevale R, et al. Low-grade endotoxemia, gut permeability and platelet activation in communityacquired pneumonia. J Infect 2016;73:107-114

14 Wada H, Thachil J, Di Nisio M, et al;The Scientific Standardization Committee on DIC of the International Society on Thrombosis Haemostasis. Guidance for diagnosis and treatment of DIC from harmonization of the recommendations from three guidelines. J Thromb Haemost 2013;11:761-767
15 Thachil J, Juffermans NP, Ranucci M, et al. ISTH DIC subcommittee communication on anticoagulation in COVID-19. J Thromb Haemost 2020;18(09):2138-2144

16 Patell R, Midha S, Kimani S, et al. Variability in institutional guidance for COVID-19-associated coagulopathy in the United States. Thromb Haemost 2020;120(12):1725-1732

17 Marietta M, Ageno W, Artoni A, et al. COVID-19 and haemostasis: a position paper from Italian Society on Thrombosis and Haemostasis (SISET). Blood Transfus 2020;18(03):167-169

18 Gerotziafas GT, Catalano M, Colgan MP, et al;Scientific Reviewer Committee. Guidance for the management of patients with vascular disease or cardiovascular risk factors and COVID-19: position paper from VAS-European Independent Foundation in Angiology/Vascular Medicine. Thromb Haemost 2020;120(12):1597-1628

19 Tritschler T, Mathieu ME, Skeith L, et al;International Network of VENous Thromboembolism Clinical Research Networks INVENTVTE. Anticoagulant interventions in hospitalized patients with COVID-19: a scoping review of randomized controlled trials and call for international collaboration. J Thromb Haemost 2020;18 (11):2958-2967

20 Patell R, Chasku T, Bauer E, et al. Pharmacologic thromboprophylaxis and thrombosis in hospitalized patients with COVID-19: a pooled analysis. Thromb Haemost 2021;121(01):76-85

21 Overstad S, Tjonnfjord E, Garabet L, et al. Venous thromboembolism and coronavirus disease 2019 in an ambulatory care setting a report of 4 cases. Thromb Res 2020;194:116-118

22 Billet H, Reyer M, Szymanski J. Anticoagulation in COVID-19: effect of enoxaparin, heparin and apixaban on mortality. Thromb Haemost 2020;120(12):1691-1699

23 Frydman GH, Streiff MB, Connors JM, Piazza G. The potential role of coagulation factor Xa in the pathophysiology of COVID-19: a role for anticoagulants as multimodal therapeutic agents. TH Open 2020;4(04):e288-e299

24 Iturbe-Hernandez T, García de Guadiana Romualdo L, Gil Ortega I, et al. Dabigatran, the oral anticoagulant of choice at discharge in patients with non-valvular atrial fibrillation and COVID-19 infection: the ANIBAL protocol. Drugs Context 2020. Doi: 10.7573/ dic.2020-8-3

25 Harenberg J, Bauersachs R, Ageno W. Does chronic treatment with oral anticoagulants ameliorate the clinical course of severe acute respiratory syndrome coronavirus 2 (SARS-CoV-2) infection in coronavirus disease 2019 (COVID-19)? Semin Thromb Hemost 2020. Doi: 10.1055/s-0040-1715091

26 Capella WH, Elliot S, Barnathanc ES, et al. Rationale and design for the study of rivaroxaban to reduce thrombotic events, hospitalization and death in outpatients with COVID-19: PREVENT-HD. Thromb Haemost 2021; In press

27 van Haren FMP, Page C, Laffey JG, et al. Nebulised heparin as a treatment for COVID-19: scientific rationale and a call for randomised evidence. Crit Care 2020;24(01):454

28 Liu J, Li J, Arnold K, Pawlinski R, Key NS. Using heparin molecules to manage COVID-2019. Res Pract Thromb Haemost 2020;4(04): 518-523

29 Harenberg J, Favaloro E. COVID-19: progression of disease and intravascular coagulation - present status and future perspectives. Clin Chem Lab Med 2020;58(07):1029-1036

30 Valeriani E, Squizzato A, Gallo A, et al. Efficacy and safety of recombinant human soluble thrombomodulin in patients with sepsis-associated coagulopathy: a systematic review and metaanalysis. J Thromb Haemost 2020;18(07):1618-1625

31 Violi F, Cacarelli G, Loffredo L, et al. Albumin supplementation dampens hypercoagulability in COVID-19. Preliminary report. Thromb Haemost 2021;121(01):102-105 